\title{
ON OPERATOR COMMUTATORS
}

\author{
DAVID C. KLEINECKE
}

The following conjecture is originally due to Kaplansky:

(1) Suppose $A$ and $T$ are elements of a Banach algebra and suppose $Q$ is the commutator of $A$ and $T$,

$$
Q=A T-T A \text {. }
$$

Further, if $Q$ commutes with $A$,

$$
Q A=A Q
$$

then $Q$ is quasi-nilpotent, that is,

$$
\lim _{n \rightarrow \infty}\left\|Q^{n}\right\| 1 / n=0 .
$$

This conjecture is cited in a Hilbert space context by Halmos [1] and, more recently, by Putnam [2], again for Hilbert space.

In this note we will prove this conjecture as it stands above. In fact, it is an easy corollary of the more general algebraic theorem (2) formulated below.

(2) Suppose operator $\Delta$ on a ring is a derivation operator, that is,

$$
\Delta(A B)=A \cdot \Delta B+\Delta A \cdot B
$$

and suppose $T$ is such that

$$
\Delta^{2} T=0
$$

Then

$$
\Delta^{n}\left(T^{n}\right)=n !(\Delta T)^{n} .
$$

Proof of (1) BY UsING (2). Let $\Delta$ be the operator on the Banach algebra defined by

$$
\Delta X=A X-X A .
$$

It is easy to see that $\Delta$ is a derivation and $\Delta^{2} T=0$ so that (2) applies. Further, since

$$
\|\Delta X\|=\|A X-X A\| \leq 2\|A\| \cdot\|X\|,
$$

$\Delta$ is a bounded operator with norm $\leq 2\|A\|$.

Now by (2)

Received by the editors February 7, 1955 and, in revised form, March 13, 1956. 


$$
Q^{n}=(\Delta T)^{n}=\frac{\Delta^{n}\left(T^{n}\right)}{n !}
$$

so that

$$
\left\|Q^{n}\right\| \leq \frac{\|\Delta\| n \cdot\|T\|^{n}}{n !} \leq \frac{2^{n}\|A\| n\|T\|^{n}}{n !} .
$$

From this follows that

$$
\lim _{n \rightarrow \infty}\left\|Q^{n}\right\|^{1 / n}=0
$$

i.e. $Q$ is quasi-nilpotent.

PROOF OF (2). Both the formulation of (2) and the proof given below are due to suggestions of the referee.

The proof is by induction. The theorem is obvious for $n=1$. Assume that

$$
\Delta^{n-1}\left(T^{n-1}\right)=(n-1) !(\Delta T)^{n-1} .
$$

Then, differentiating, $\Delta^{n}\left(T^{n-1}\right)=0$. From this follows, by Leibnitz's rule,

$$
\begin{aligned}
\Delta^{n}\left(T^{n}\right) & =\Delta^{n}\left(T \cdot T^{n-1}\right)=\sum_{i=0}^{n}\left(\begin{array}{c}
n \\
i
\end{array}\right) \Delta^{i} T \cdot \Delta^{n-i}\left(T^{n-1}\right) \\
& =T \cdot \Delta^{n}\left(T^{n-1}\right)+n \cdot \Delta T \cdot \Delta^{n-1}\left(T^{n-1}\right) \\
& =n \cdot \Delta T \cdot(n-1) !(\Delta T)^{n-1} \\
& =n !(\Delta T)^{n} .
\end{aligned}
$$

\section{REFERENCES}

1. P. R. Halmos, Commutators of operators, Amer. J. Math. vol. 76 (1954) pp. 191-198.

2. C. R. Putnam, On the spectra of commutators, Proc. Amer. Math. Soc. vol. 5 (1954) pp. 929-931.

SANDia CoRporation 